\title{
Modeling the Quality and Quantity of Runoff in a Highly Urbanized Catchment Using Storm Water Management Model
}

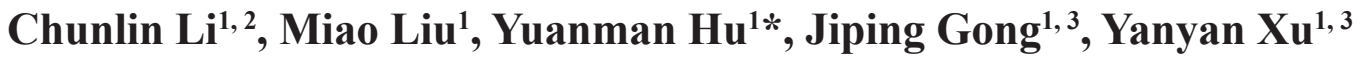 \\ 'Institute of Applied Ecology, Chinese Academy of Sciences, Shenyang 110016, China \\ ${ }^{2}$ Key Laboratory of Pollution Ecology and Environmental Engineering, Institute of Applied Ecology, \\ Chinese Academy of Sciences \\ ${ }^{3}$ University of Chinese Academy of Sciences, Beijing 100049, China
}

Received: 3 June 2015

Accepted: 24 November 2015

\begin{abstract}
As urbanization increases, urban runoff becomes an increasingly more important component of urban non-point pollution. In this study, the Storm Water Management Model was used to simulate the quantity and quality of runoff in a highly urbanized catchment. Data from three rainfall events were collected and used for model calibration and validation. Model performance was assessed using the Nash-Sutcliffe coefficient, relative error, and coefficient of determination. The modified Morris screening method was used for local sensitivity analysis. Sensitivity analysis results showed that the destore imperv and condit roughness parameters had the most influence on the hydrology and hydraulic module. Road exponent was the most sensitive parameter in determining TSS quantity and peak concentration. The calibration and verification results indicated that the model structure and parameters fitted the runoff-producing pattern. The total simulation accuracies of TSS, TN, TP, and COD loads, as assessed by the $\mathrm{R}^{2}$ value, were 0.82 , $0.87,0.72$, and 0.94 , respectively.
\end{abstract}

Keywords: buildup and washoff, rainfall runoff, Storm Water Management Model, urban non-point pollution

\section{Introduction}

Increases in urbanization and conversion of land for urban use has resulted in increased areas of impervious surfaces and, as a consequence, increases in runoff volumes and peak flow rates [1]. Studies have shown that urban stormwater runoff contains a variety of pollutants such as sediment, organic material, microorganisms,

*e-mail: huym@iae.ac.cn nutrients, and heavy metals [2-4], which can all seriously impact public health and threaten environmental quality [5]. In urban areas, pollutants accumulate on urban surfaces and are then washed off by stormwater during wet weather [6]. Urban runoff pollution problems are more difficult to control than steady-state point discharges because of intermittent and unpredictable rainfall and runoff, the large variety of pollutants involved, and the complex environmental setting [7-10].

Regular monitoring studies cannot provide sufficient data to support urban non-point pollution research. Because 
of the increased need to control non-point pollution and to reuse stormwater, hydrological models that can provide a thorough understanding of the basic hydrological and hydraulic processes are increasingly applied in urban settings [11]. Field observation data have played an important role in developing urban hydrological models [12]. Since it was developed by the U.S. Environmental Protection Agency, the Storm Water Management Model (SWMM) has become one of the most widely used rainfallrunoff models for simulating hydrological processes and water quality in urban areas [13-15]. SWMM has been applied to all types of stormwater management - from urban drainage [16] to flood routing [17].

Shenyang, an established industrial base in northeastern China, has experienced rapid urbanization. Various policies have been implemented in recent years, including the revitalization of the old industrial base in Northeastern China, that have resulted in a rapid increase in the amount of impervious surfaces in the area. As a result, non-point source pollution from urban runoff is an increasingly serious problem. Information about runoff in urban catchments is important for supporting pollution control; therefore, in this study, the quantity and quality of stormwater in Shenyang were monitored and simulated. The aim of this study was to calibrate and validate SWMM, a highly developed urban catchment model, using monitored data of runoff volume and pollutant concentration. The sensitivity of the inputs and model parameters on the model outputs were also examined.

\section{Materials and Methods}

\section{Study Area Description}

The study catchment is a residential-educational mixed district in the city of Shenyang (41 $11^{\prime} 51^{\prime \prime}$ $\left.43^{\circ} 02^{\prime} 13^{\prime \prime} \mathrm{N}, 122^{\circ} 25^{\prime} 09^{\prime \prime}-123^{\circ} 48^{\prime} 24^{\prime \prime} \mathrm{E}\right)$, the largest and most important industrial city in northeastern China. It has a temperate continental monsoon climate. The mean annual precipitation is $510-680 \mathrm{~mm}$, most of which falls from June to August. The catchment area, which comprises high-density residential (56.1\%) and educational (43.9\%) areas, is $24.2 \mathrm{hm}^{2}$. Impervious surfaces cover about $69.3 \%$ of the whole catchment, and gently slope from southeast to northwest with an average slope of $0.1 \%$. The sewer system is separated and is made of standard concrete pipes.

Based on the hydrological characteristics in the SWMM manual, the study area was simplified into 38 subcatchments and 34 junctions for simulation purposes (Fig. 1). All of the subcatchments had separate sewage drainage systems, and the stormwater runoff flowed past conduits to the final outfall.

\section{Storm Runoff Monitoring and Sampling}

Rainfall data was monitored using a tipping bucket rain gauge, which could accurately measure rainfall of $0.25 \mathrm{~mm}$ ( 0.01 in), sited on the grass of subcatchment S21. Samples

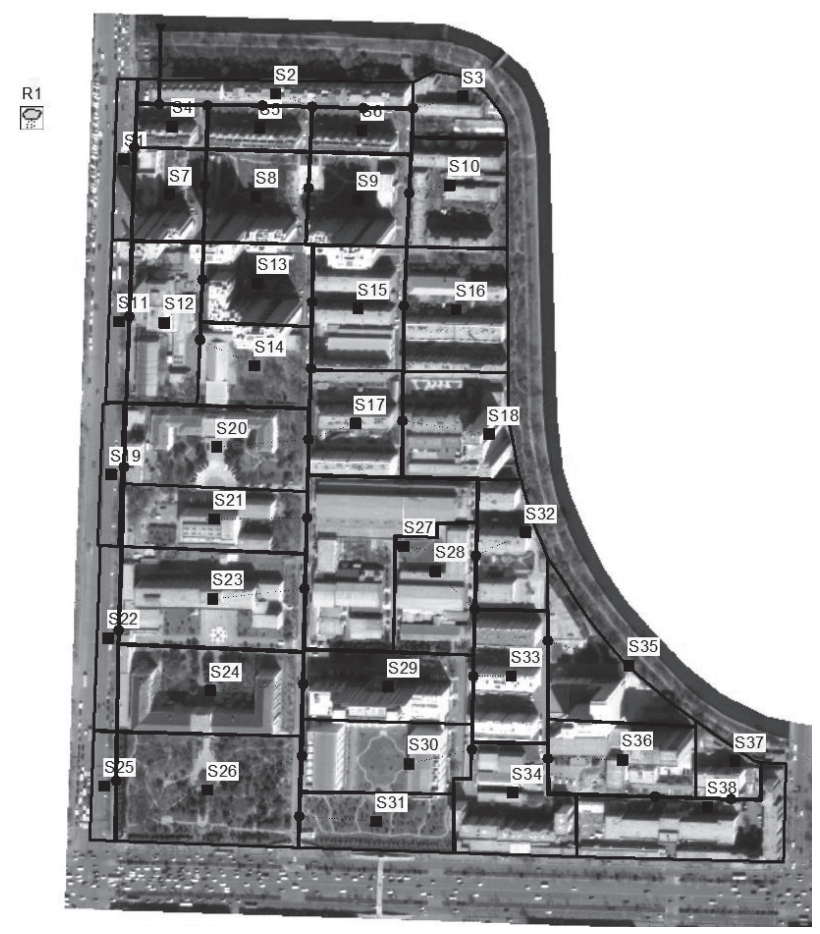

Fig. 1. Generalized distribution of the study area.

were collected manually using polyethylene bottles in three rainfall events from July to August 2012. The main characteristics of the rainfall events are summarized in Table 1. Precipitation amounts ranged from 4.6 to $33.8 \mathrm{~mm}$, and the average rainfall intensity ranged from 2.4 to $12.1 \mathrm{~mm} / \mathrm{h}$. The antecedent dry weather periods ranged from five to 10 days (Table 1 ).

Samples of roof runoff were collected at the outfall. Once runoff flow was observed, we collected samples every $10 \mathrm{~min}$ for the first $60 \mathrm{~min}$, every $30 \mathrm{~min}$ between 60 and $180 \mathrm{~min}$, and then every $60 \mathrm{~min}$ beyond $180 \mathrm{~min}$. The samples were collected, treated, and analyzed in the laboratory within $24 \mathrm{~h}$. All the storm runoff samples were analyzed for total suspended solids (TSS), chemical oxygen demand (COD), total nitrogen (TN), and total phosphorus (TP) using standard methods [18].

\section{Model Description}

SWMM, the storm water management model developed by the EPA, was used for this study. It is a dynamic rainfall-runoff simulation model that can be used for either single events or long-term (continuous) simulation of runoff quantity and quality, primarily from urban areas [19]. SWMM comprises four components, namely runoff, storage/treatment, transport, and extran. The runoff component of SWMM operates on a collection of subcatchment areas that receive precipitation and generate runoff and pollutant loads. The transport component of SWMM transports this runoff through a system of pipes, channels, storage/treatment devices, pumps, and regulators. SWMM tracks the quantity and 
Table 1. Characteristics of rainfall events.

\begin{tabular}{|c|c|c|c|c|c|}
\hline Date (y-m-d) & $\begin{array}{c}\text { Rainfall } \\
(\mathrm{mm})\end{array}$ & $\begin{array}{c}\text { Duration } \\
(\mathrm{h})\end{array}$ & $\begin{array}{c}\text { Average intensity } \\
(\mathrm{mm} / \mathrm{h})\end{array}$ & $\begin{array}{c}\text { Max rainfall intensity } \\
(\mathrm{mm} / \mathrm{h})\end{array}$ & $\begin{array}{c}\text { Antecedent dry weather period } \\
(\mathrm{d})\end{array}$ \\
\hline $2012-07-10$ & 16.0 & 6.7 & 2.4 & 5.0 & 5 \\
\hline $2012-07-22$ & 33.8 & 2.8 & 12.1 & 28.7 & 10 \\
\hline $2012-08-28$ & 4.6 & 3.5 & 1.3 & 2.4 & 9 \\
\hline
\end{tabular}

quality of runoff generated within each subcatchment. Information was collected on the flow rate, flow depth, and quality of the water in each pipe and channel during a simulation period comprised of multiple time steps.

\section{Model Parameterization}

Taking into consideration the characteristics of the study catchment and the distribution of the manholes, the catchment was divided into 38 subcatchments, which represents a fairly detailed discretization. Horton's equation was used for infiltration, and flow routing computations were based on the dynamic wave theory. The buildup and washoff of pollutants were calculated by exponential equations. The slopes of individual subcatchments were calculated from the digital elevation model (DEM) of the catchment. The area of the subcatchments and the percentage of impervious surfaces were calculated from a land use map in ArcGIS. The properties of the conduit and junctions were obtained from the drainage pipe network data. The width of the overland flow path is an important parameter in the model, and is very sensitive to the simulated runoff volume. The characteristic width of each catchment is difficult to determine, and various methods can be used to calculate it, as follows:

$$
\begin{aligned}
& \text { Width }=1.7 \times \operatorname{MAX}(H, W) \\
& \text { Width }=K \times \sqrt{A} \quad(0.2<K<5)
\end{aligned}
$$

$$
\begin{gathered}
\text { Width }=K \times P \quad(0<K<1) \\
\text { Width }=A / L
\end{gathered}
$$

...where Width is the characteristic width of the overland flow, $H$ is the height of the subcatchment, $W$ is the width of the subcatchment, $K$ is the coefficient, $A$ is the area of the subcatchment, $P$ is the perimeter of the subcatchment, and $L$ is flow length. In this study we used the second method and $K$ was rated for calculations of the characteristic width.

The initial values and range of values for Manning's roughness coefficient, the width of the overland flow path, depression storage, infiltration parameters of Horton's equation, and buildup and washoff parameters of pollutants were identified from the user's manual and previous studies before calibration [19-21] (Table 2).

The water-quality component of SWMM includes buildup and washoff. The amount of buildup is a function of the preceding dry weather days and can be computed using either a power function, exponential function, saturation function, or an external time series. Pollutant washoff from a given land use category occurs during wet weather periods and can be described by an exponential function, rating curve function, or an event mean concentration function. In this paper, we used the exponential function to calculate the accumulation and washoff of pollutants. The land use of the study area was generally grouped into three categories: road, roof, and greenfield. Each land use type had two buildup and two

Table 2. Calibration parameters for SWMM hydrology and hydraulic module.

\begin{tabular}{|c|c|c|c|c|}
\hline Number & Name of parameter & Meaning & Value range & Initial value \\
\hline 1 & Width-K & flow width coefficient & $0.2-5$ & 2 \\
\hline 2 & N-Imperv & Manning's roughness coefficient for impervious area & $0.011-0.015$ & 0.012 \\
\hline 3 & N-Perv & Manning's roughness coefficient for pervious area & $0.05-0.8$ & 0.13 \\
\hline 4 & Destore-Imperv & Depth of depression storage on impervious area & $0-3$ & 1 \\
\hline 5 & Destore-Perv & Depth of depression storage on pervious area & $3-10$ & 6 \\
\hline 6 & Conduit Roughness & Manning's roughness coefficient for conduit & $0.011-0.024$ & 0.014 \\
\hline 7 & Max. Infil. Rate & Maximum rate on the Horton infiltration curve & $10-100$ & 30 \\
\hline 8 & Min. Infil. Rate & Minimum rate on the Horton infiltration curve & $0-10$ & 2 \\
\hline 9 & Decay Constant & Decay constant for the Horton infiltration curve & $0-7$ & 2 \\
\hline 10 & Drying Time & Time for a fully saturated soil to completely dry & $1-7$ & 5 \\
\hline
\end{tabular}


Table 3. Calibration parameters and their initial values for the SWMM water quality module.

\begin{tabular}{|c|c|c|c|}
\hline Number & Name of parameter & Meaning & Initial value \\
\hline 1 & Road Max Buildup & Maximum possible buildup of road & 000 \\
\hline 2 & Road Rate Constant & Rate constant of buildup of road & 0.012 \\
\hline 3 & Road Coefficient & Washoff coefficient of road & 2 \\
\hline 4 & Road Exponent & Runoff exponent of road & 300 \\
\hline 5 & Roof Max Buildup & Maximum possible buildup of roof & 0.7 \\
\hline 6 & Roof Rate Constant & Rate constant of buildup of roof & 0.01 \\
\hline 7 & Roof Coefficient & Washoff coefficient of roof & 1.8 \\
\hline 8 & Roof Exponent & Runoff exponent of roof & 150 \\
\hline 9 & Green Max Buildup & Maximum possible buildup of greenfield & 0.6 \\
\hline 10 & Green Rate Constant & Rate constant of buildup of greenfield & 0.006 \\
\hline 11 & Green Coefficient & Washoff coefficient of greenfield & 1.6 \\
\hline
\end{tabular}

washoff parameters that could be used in the sensitivity analysis and calibration (Table 3 ).

\section{Sensitivity Analysis}

Sensitivity analysis is a crucial procedure that supports parameter identification. This procedure supported the identification of the most sensitive parameters in the model, thereby allowing these parameters to be used for calibration $[22,23]$. Sensitivity analyses can be broadly grouped into local and global approaches [24]. In this paper, the modified Morris screening method was used to carry out local sensitivity analyses. The Morris screening method provides sensitivity estimates of the entire influence of a factor on the output and a total measure of the sensitivity of curvature and interactions between factors [25]. Each of the parameter values varies while all others remain fixed, and the average rate of change is the sensitivity of the parameter. The formula is as follows:

$$
S=\left|\sum_{i=1}^{n} \frac{\left(Y_{i+1}-Y_{i}\right) / Y_{i}}{\left(P_{i+1}-P_{i}\right) / P_{i}} / n\right|
$$

...where $S$ is the sensitivity of each parameter, $Y_{i}$ is the output value of the i-th model run, $Y_{i+1}$ is output value of the $\mathrm{i}+1$-th model run, $P_{i}$ is the change in the parameter with respect to the initial parameter for the i-th model run, $P_{i+1}$ is the change in the parameter with respect to the initial parameter for the $i+1$-th model run, and $n$ is the number of model runs. The observed rainfall data were used for sensitivity analysis. Sensitivity analysis was carried out individually for the total flows and peak flows.

\section{Goodness of Fit Criteria}

The model performance during the sensitivity analysis, parameter optimization, and calibration and validation stages was evaluated using criteria that had been applied in other similar studies $[20,26]$. The Nash-Sutcliffe coefficient $\left(\mathrm{R}_{\mathrm{NS}}\right)$, relative error (RE), and coefficient of determination $\left(\mathrm{R}^{2}\right)$ are commonly used to evaluate model performance and are shown in Equations 6-8, respectively.

$$
\begin{aligned}
& R_{N S}=1-\frac{\sum_{t=1}^{n}\left(q_{t}^{o b s}-q_{t}^{s i m}\right)^{2}}{\sum_{t=1}^{n}\left(q_{t}^{o b s}-\overline{q_{t}^{o b s}}\right)^{2}} \\
& R E=\frac{\sum_{t=1}^{n}\left|q_{t}^{o b s}-q_{t}^{s i m}\right|}{n} \\
& \sum_{t=1}^{n} q_{t}^{o b s}, \text { and } \\
& R^{2}=\left(\frac{\sum_{t=1}^{n}\left(q_{t}^{o b s}-\overline{q_{t}^{o b s}}\right)\left(q_{t}^{s i m}-\overline{q_{t}^{s i m}}\right)}{\sqrt{\sum_{t=1}^{n}\left(q_{t}^{o b s}-\overline{q_{t}^{o b s}}\right)^{2}} \sqrt{\sum_{t=1}^{n}\left(q_{t}^{\text {sim }}-\overline{q_{t}^{s i m}}\right)^{2}}}\right)^{2}
\end{aligned}
$$

...where $q_{t}^{\text {obs }}$ is the observed flow at time $t, q_{t}^{\text {sim }}$ is the predicted flow at time $t, q_{t}^{o b s}$ is the average observed discharge, $q_{t}^{s i m}$ is the average predicted discharge, $t$ is time, and $n$ is the total number of time steps.

$\mathrm{R}_{\mathrm{NS}}$ measures the goodness of fit by comparing both the volume and the shape of the discharge profile [27, 28]. It also provides a comparison between the efficiency of the chosen model and a description of the data as the mean of the observations $[29,30]$. The optimal simulation value occurs when the $R_{N S}$ is close to 1 . RE is the error percentage (the ratio of absolute error and the observed values) that shows the reliability of the predicted value. $\mathrm{R}^{2}$ 
indicates how well the observed values are replicated by the simulation, as a proportion of the total variation of the outcomes explained by the simulation.

\section{Results and Discussion}

\section{Sensitivity Analysis Results}

The three events used for model calibration and validation were also used for sensitivity analysis. The sensitivity coefficients of the hydrological and hydraulic parameters on total flow and peak flow are listed in Table 4. The parameters that had the most influence on the hydrology and hydraulic component were the depth of depression storage on impervious area, known as destore imperv, and condit roughness. Destore imperv was the most sensitive parameter in the determination of the total flow, and had a sensitivity coefficient value of 0.142 . Condit roughness was highly sensitive to total flow and was the most sensitive parameter to peak flow. It accounted for $11.3 \%$ of the variance in the predicted total flow and $15.6 \%$ of the variance of the predicted peak flow, respectively. Destore-Imperv and Width-K also had high sensitivity coefficients for peak flow, and accounted for $9.8 \%$ and $7.4 \%$ of the variance of the predicted peak flow. Catchment width had a strong influence on peak flow but had less influence on total flow.

TSS was chosen to represent the water quality pollutants in the sensitivity analysis. There was considerable variation in the sensitivities of the buildup and washoff parameters of the three land use types (road, roof, and greenfield) on the quantity and peak concentrations of TSS (Table 5).

The sensitivities of the road and roof water quality parameters were significantly higher than those of the greenfield parameters. Road Exponent was the most sensitive parameter for the quantity and peak concentrations of TSS. The max buildup and exponent of the road and roof

Table 4. Sensitivity coefficients of hydrological and hydraulic parameters.

\begin{tabular}{|c|c|c|c|}
\hline No. & Parameters & $\begin{array}{c}\text { Sensitivity to } \\
\text { total flow }\end{array}$ & $\begin{array}{c}\text { Sensitivity to } \\
\text { peak flow }\end{array}$ \\
\hline 1 & Width-K & 0.034 & 0.074 \\
\hline 2 & N-Imperv & 0.039 & 0.049 \\
\hline 3 & N-Perv & 0.008 & 0.003 \\
\hline 4 & Destore-Imperv & 0.142 & 0.098 \\
\hline 5 & Destore-Perv & 0.007 & 0.003 \\
\hline 6 & Condit Roughness & 0.113 & 0.156 \\
\hline 7 & Max. Infil. Rate & 0.023 & 0.003 \\
\hline 8 & Min. Infil. Rate & 0.008 & 0.001 \\
\hline 9 & Decay Constant & 0.029 & 0.003 \\
\hline 10 & Drying Time & 0.001 & 0.001 \\
\hline
\end{tabular}

Table 5 . Sensitivity analysis of water quality parameters.

\begin{tabular}{|c|c|c|c|}
\hline No. & Parameters & $\begin{array}{c}\text { Sensitivity to } \\
\text { TSS quantity }\end{array}$ & $\begin{array}{c}\text { Sensitivity } \\
\text { to TSS peak } \\
\text { concentration }\end{array}$ \\
\hline 1 & Road Max Buildup & 0.511 & 0.602 \\
\hline 2 & Road Rate Constant & 0.012 & 0.015 \\
\hline 3 & Road coefficient & 0.349 & 0.099 \\
\hline 4 & Road Exponent & 0.672 & 1.610 \\
\hline 5 & Roof Max Buildup & 0.424 & 0.358 \\
\hline 6 & Roof Rate Constant & 0.017 & 0.015 \\
\hline 7 & Roof coefficient & 0.346 & 0.193 \\
\hline 8 & Roof Exponent & 0.653 & 0.899 \\
\hline 9 & Green Max Buildup & 0.065 & 0.040 \\
\hline 10 & Green Rate Constant & 0.004 & 0.003 \\
\hline 11 & Green coefficient & 0.056 & 0.034 \\
\hline 12 & Green Exponent & 0.086 & 0.171 \\
\hline
\end{tabular}

had high sensitivity coefficients and were key parameters for predicting the quantity and peak concentrations of TSS. The buildup and washoff parameters of the greenfield area were relatively insensitive, mainly because the greenfield area in the study area was small and the pollution loads were small.

\section{Model Calibration and Validation}

Based on the sensitivity analysis results for the model parameters, the most sensitive parameters were optimized. The less sensitive parameters were later optimized once the model output was controlled within a reasonable range. The model was repeatedly debugged to find the optimal parameters until the simulated and measured values were identical. The observed flow and water quality data for the storm events on 10 July and 28 August were used for the calibration, while the flow and water quality data from the 22 July 2012 event were used to validate the SWMM model.

\section{Hydrological Parameters}

The calibration and validation of the hydrological parameters gave excellent results. The model provided good simulation of both the volume and instantaneous peaks. $\mathrm{R}_{\mathrm{NS}}$ values greater than 0.87 were deemed acceptable, and the RE values of the simulated outflow were less than $30 \%$ of the observed outflow, which shows that the simulated curves were a good fit for the observed curves. The simulated and observed values for runoff were correlated, and the $\mathrm{R}^{2}$ values of the three events were $0.86,0.90$, and 0.87 , respectively (Fig. 2). The calibration and verification results indicated that the model structure and parameters matched the runoff-producing pattern and that the calibrated model was suitable 

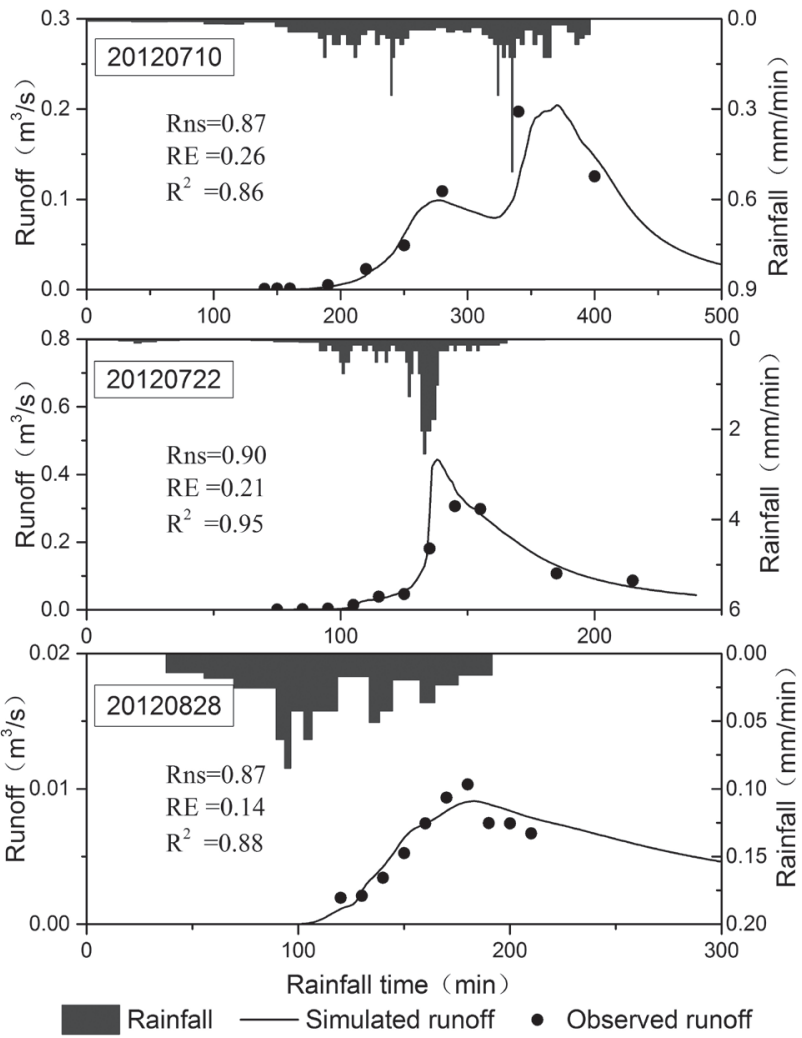

Fig. 2. Comparison between the simulated and observed values in the SWMM model.

for simulating storm runoff in the study area. The optimal parameters of the hydraulic module are shown in Table 6 .

\section{Water Quality Parameters}

To achieve the aim of the study, the hydrological module was calibrated to estimate non-point pollution in the study area. After the calibration was completed, the

Table 6. Optimal parameters of the hydrological module in the SWMM model.

\begin{tabular}{|c|c|c|}
\hline No. & Parameters & $\begin{array}{c}\text { Optimal } \\
\text { parameters }\end{array}$ \\
\hline 1 & Width-K & 4 \\
\hline 2 & N-Imperv & 0.013 \\
\hline 3 & N-Perv & 0.15 \\
\hline 4 & Destore-Imperv & 1 \\
\hline 5 & Destore-Perv & 3 \\
\hline 6 & Condit Roughness & 0.012 \\
\hline 7 & Max. Infil. Rate & 40 \\
\hline 8 & Min. Infil. Rate & 5 \\
\hline 9 & Decay Constant & 7 \\
\hline 10 & Drying Time & 7 \\
\hline
\end{tabular}

optimal hydrological parameters were input and used to calibrate and validate the water quality parameters. The water quality parameters were calibrated in two steps. In the first step, the general range of the buildup and washoff parameters were obtained from previous studies [31], following which the initial values of the parameters were input into the model. During the calibration process, the buildup and washoff parameters were adjusted so that they were within the range of the established values. In the second step, the most sensitive parameters from the sensitivity analysis of the model parameters were manually adjusted for all the pollutants that contributed to the outlet monitor until the SWMM model matched the observed values. When the simulated values were approximately equal to the measured values, the model was further calibrated by adjusting the less sensitive parameters. Finally, through a two-step adjustment process, the calibration of the four pollutants was completed.

Correlations were determined by the slope of the best fit line through a plot of the observed and simulated values. The water quality calibration shows a good fit between the observed and simulated data (Fig. 3). The total simulation accuracies of the TSS, TN, TP, and COD loads, as assessed by the $\mathrm{R}^{2}$ values, were $0.82,0.87,0.72$, and 0.94 , respectively. $R_{N S}$ coefficients, $R E$ values, and $R^{2}$ of the four pollutants for the calibration and validation steps are shown in Table 7. For the calibration, the $\mathrm{R}_{\mathrm{NS}}$ values ranged from 0.64 to 0.96 , while the $\mathrm{RE}$ values ranged from 0.07 to 0.30 . $\mathrm{R}^{2}$ also showed similar simulation accuracy. The values of $\mathrm{R}^{2}$ were all greater than 0.7 , and most were greater than 0.9 , which indicated that most of the total variation of the outcomes was explained by the simulation. With the exception of TP, the simulations of the other three pollutants were confirmed, and although the simulated results were slightly lower than the calibration results, the simulation accuracy was still good. The $\mathrm{R}_{\mathrm{NS}}$ values were above 0.74 , $R E$ was less than 0.31 , and $R^{2}$ values were greater than 0.77 . The weak goodness-of-fit for TP suggests that in this study area, TP cannot be modelled by simply using rainfall data from several events. It may be possible to improve the validation results with more observed rainfall data.

The optimal parameters of the water quality module of TSS, TN, TP, and COD obtained from the calibration and validation are shown in Table 8.

\section{Conclusions}

In this study, the SWMM model was successfully used to model the quantity and quality of runoff in a highly urbanized area of northeastern China. Data from rainfall events were used to calibrate and validate the model. Sensitivity analysis showed that the parameters that had most influence on the hydrology and hydraulic module were destore imperv and condit roughness. The road and roof quality parameters were significantly more sensitive than the greenfield parameters. The Road Exponent was the most sensitive parameter for estimating the quantity 

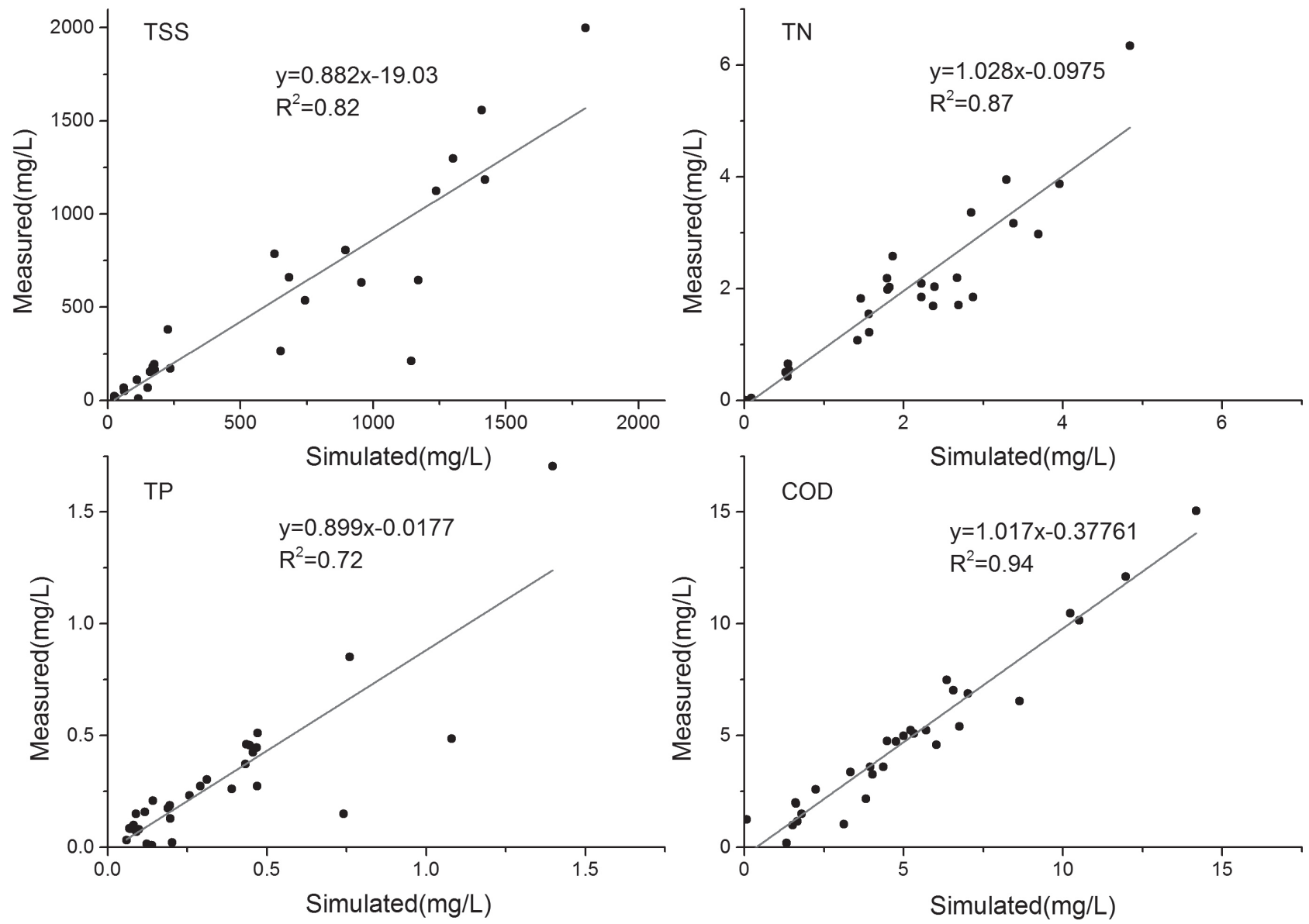

Fig. 3. Correlation between the observed and simulated pollutant data.

Table 7. Evaluation of the accuracy of the water-quality module simulation.

\begin{tabular}{|c|c|c|c|c|c|}
\hline & Pollutants & Rain data & $\begin{array}{c}\text { Nash-Sutcliffe coefficients } \\
\left(\mathrm{R}_{\mathrm{NS}}\right)\end{array}$ & $\begin{array}{l}\text { Relative errors } \\
\text { (RE) }\end{array}$ & $\begin{array}{l}\text { Coefficients of determination } \\
\qquad\left(\mathrm{R}^{2}\right)\end{array}$ \\
\hline \multirow{8}{*}{ Calibration } & \multirow{2}{*}{ TSS } & 20120710 & 0.74 & 0.30 & 0.90 \\
\hline & & 20120828 & 0.94 & 0.07 & 0.94 \\
\hline & \multirow{2}{*}{$\mathrm{TN}$} & 20120710 & 0.96 & 0.17 & 0.96 \\
\hline & & 20120828 & 0.64 & 0.14 & 0.79 \\
\hline & \multirow{2}{*}{$\mathrm{TP}$} & 20120710 & 0.91 & 0.24 & 0.91 \\
\hline & & 20120828 & 0.64 & 0.12 & 0.71 \\
\hline & \multirow{2}{*}{ COD } & 20120710 & 0.95 & 0.08 & 0.97 \\
\hline & & 20120828 & 0.76 & 0.15 & 0.76 \\
\hline \multirow{4}{*}{ Validation } & \multirow{2}{*}{$\begin{array}{l}\text { TSS } \\
\text { TN }\end{array}$} & 20120722 & 0.74 & 0.31 & 0.77 \\
\hline & & 20120722 & 0.75 & 0.25 & 0.82 \\
\hline & \multirow{2}{*}{$\begin{array}{l}\text { TP } \\
\text { COD }\end{array}$} & 20120722 & 0.66 & 0.69 & 0.72 \\
\hline & & 20120722 & 0.76 & 0.26 & 0.85 \\
\hline
\end{tabular}

and peak concentrations of TSS. The calibration and verification results indicate that the model structure and parameters fitted the runoff producing pattern. The total simulation accuracy of the TSS, TN, TP, and COD loads, as assessed by the $\mathrm{R}^{2}$ values, were $0.82,0.87,0.72$, and 0.94 , respectively. 
Table 8. Optimal parameters of the water quality module in the SWMM model.

\begin{tabular}{|c|c|c|c|c|c|}
\hline No. & Parameters & TSS & TN & TP & COD \\
\hline 1 & Road Max Buildup & 370 & 4 & 0.2 & 96 \\
\hline 2 & Road Rate Constant & 0.5 & 0.7 & 0.1 & 0.2 \\
\hline 3 & Road coefficient & 0.003 & 0.07 & 0.02 & 0.002 \\
\hline 4 & Road Exponent & 1.9 & 1.7 & 1.8 & 1.8 \\
\hline 5 & Roof Max Buildup & 300 & 2 & 0.14 & 54 \\
\hline 6 & Roof Rate Constant & 0.4 & 0.5 & 0.2 & 0.3 \\
\hline 7 & Roof coefficient & 0.005 & 0.001 & 0.003 & 0.009 \\
\hline 8 & Roof Exponent & 1.4 & 1.3 & 1.9 & 1.5 \\
\hline 9 & Green Max Buildup & 100 & 9 & 0.4 & 25 \\
\hline 10 & Green Rate Constant & 0.3 & 0.5 & 0.3 & 0.1 \\
\hline 11 & Green coefficient & 0.005 & 0.004 & 0.001 & 0.01 \\
\hline 12 & Green Exponent & 1.6 & 1.2 & 2 & 1.3 \\
\hline
\end{tabular}

\section{Acknowledgements}

Funding for this project was provided by the Natural Science Foundation of China (Nos. 41501198 and 41171155) and the Open Research Fund Program (No. Y5ZDS121YC)

\section{References}

1. CHUNLIN L., MIAO L., YUANMAN H., JIPING G., FENGYUN S., YANYAN X. Characterization and first flush analysis in road and roof runoff in Shenyang, China. Water Science \& Technology, 70, 397, 2014.

2. SELVAKUMAR A., BORST M. Variation of microorganism concentrations in urban stormwater runoff with land use and seasons. Journal of Water and Health, 4, 109, 2006.

3. KROMETIS L., DRUMMEY P., CHARACKLIS G., SOBSEY M. Impact of Microbial Partitioning on Wet Retention Pond Effectiveness. Journal of Environmental Engineering, 135, 758, 2009.

4. YANG X.L., LI T.K., HUA K.K., ZHANG Y.L. Investigation of First Flushes in a Small Rural-Agricultural Catchment. Polish Journal of Environmental Studies, 24, 381, 2015.

5. RAUCH W., LEDIN A., ERIKSSON E., DELETIC A., HUNT III W.F. Stormwater in urban areas. Water Research, 46, 6588, 2012

6. ZHANG Q., WANG X., HOU P., WAN W., LI R., REN Y., OUYANG Z. Quality and seasonal variation of rainwater harvested from concrete, asphalt, ceramic tile and green roofs in Chongqing, China. Journal of Environmental Management, 132, 178, 2014.

7. CHARACKLIS G.W., WIESNER M.R. Particles, metals, and water quality in runoff from large urban watershed. Journal of Environmental Engineering-Asce, 123, 753, 1997.

8. GERMAN J., SVENSSON G. Metal content and particle size distribution of street sediments and street sweeping waste. Water Science and Technology, 46, 191, 2002.
9. VAZE J., CHIEW F. Nutrient Loads Associated with Different Sediment Sizes in Urban Stormwater and Surface Pollutants. Journal of Environmental Engineering, 130, 391, 2004.

10. WALSH C.J., FLETCHER T.D., BURNS M.J. Urban Stormwater Runoff: A New Class of Environmental Flow Problem. PLoS ONE, 7, e45814, 2012.

11. PETERSON E.W., WICKS C.M. Assessing the importance of conduit geometry and physical parameters in karst systems using the storm water management model (SWMM). Journal of Hydrology, 329, 294, 2006.

12. OUYANG W., GUO B., HAO F., HUANG H., LI J., GONG Y. Modeling urban storm rainfall runoff from diverse underlying surfaces and application for control design in Beijing. Journal of Environmental Management, 113, 467, 2012.

13. BARCO J., WONG K.M., STENSTROM M.K. Automatic calibration of the US EPA SWMM model for a large urban catchment. Journal of Hydraulic Engineering-Asce, 134, 466, 2008.

14. SHORSHANI M.F., BONHOMME C., PETRUCCI G., ANDR M., SEIGNEUR C. Road traffic impact on urban water quality: a step towards integrated traffic, air and stormwater modelling. Environmental Science and Pollution Research, 21, 5297, 2014.

15. WALSH T.C., POMEROY C.A., BURIAN S.J. Hydrologic modeling analysis of a passive, residential rainwater harvesting program in an urbanized, semi-arid watershed. Journal of Hydrology, 508, 240, 2014.

16. ALIAS N., LIU A., EGODAWATTA P., GOONETILLEKE A. Sectional analysis of the pollutant wash-off process based on runoff hydrograph. Journal of Environmental Management, 134, 63, 2014

17. HSU M.H., CHEN S.H., CHANG T.J. Inundation simulation for urban drainage basin with storm sewer system. Journal of Hydrology, 234, 21, 2000.

18. CEPA. Analyses methods for monitoring water and wastewater $\left(4^{\text {th }}\right.$ ed). Beijing: Environmental Science Press, 2002.

19. ROSSMAN L.A. Storm water management model user's manual, version 5.0. National Risk Management Research Laboratory, Office of Research and Development, US Environmental Protection Agency, 2010.

20. CHOW M.F., YUSOP Z., TORIMAN M.E. Modelling runoff quantity and quality in tropical urban catchments using Storm Water Management Model. International Journal of Environmental Science and Technology, 9, 737, 2012.

21. BORRIS M., VIKLANDER M., GUSTAFSSON A.M., MARSALEK J. Modelling the effects of changes in rainfall event characteristics on TSS loads in urban runoff. Hydrological Processes, 28, 1787, 2014.

22. BLASONE R.-S., MADSEN H., ROSBJERG D. Uncertainty assessment of integrated distributed hydrological models using GLUE with Markov chain Monte Carlo sampling. Journal of Hydrology, 353, 18, 2008.

23. VAN DER STERREN M., RAHMAN A., RYAN G. Modeling of a lot scale rainwater tank system in XPSWMM: A case study in Western Sydney, Australia. Journal of Environmental Management, 141, 177, 2014.

24. SALTELLI A., TARANTOLA S., CAMPOLONGO F. Sensitivity analysis as an ingredient of modeling. Statistical Science, 377, 2000.

25. CAMPOLONGO F., BRADDOCK R. Sensitivity analysis of the IMAGE Greenhouse model. Environmental Modelling \& Software, 14, 275, 1999. 
26. KREBS G., KOKKONEN T., VALTANEN M., KOIVUSALO H., SETALA H. A high resolution application of a stormwater management model (SWMM) using genetic parameter optimization. Urban Water Journal, 10, 394, 2013.

27. ARABI M., GOVINDARAJU R.S., HANTUSH M.M. A probabilistic approach for analysis of uncertainty in the evaluation of watershed management practices. Journal of Hydrology, 333, 459, 2007.

28. THANAPAKPAWIN P., RICHEY J., THOMAS D., RODDA S., CAMPBELL B., LOGSDON M. Effects of landuse change on the hydrologic regime of the Mae Chaem river basin, NW Thailand. Journal of Hydrology, 334, 215, 2007.
29. NASH J., SUTCLIFFE J. River flow forecasting through conceptual models part I - A discussion of principles. Journal of Hydrology, 10, 282, 1970.

30. ZHAO D., CHEN J., WANG H., TONG Q. Application of a sampling based on the combined objectives of parameter identification and uncertainty analysis of an urban rainfallrunoff model. Journal of Irrigation and Drainage Engineering, 139, 66, 2012.

31. PARK S., LEE K., PARK I., HA S. Effect of the aggregation level of surface runoff fields and sewer network for a SWMM simulation. Desalination, 226, 328, 2008. 